\title{
USE OF CHOLINESTERASE ACTIVITY AS A BIOMARKER OF EXPOSURE TO ENDOSULFAN IN A TROPICAL FISH SPECIES
}

\author{
KLEMZ, C. ${ }^{1}$; SILVA DE ASSIS, H.C. ${ }^{1}$ \\ 1'Departmento de Farmacologia - UFPR. E-mail: cklmz@yahoo.com.
}

The extensive use of pollutant chemical substances in most of the anthropic activities poses severe risk to ecosystems health. Monitoring of environmental pollution can be achieved through the use of biomarkers. Animal biochemical or physiological patterns act as early warning signals for the diagnostic of environmental pollution before ecosystem level damage occurs. Cholinesterase activity is a biomarker of exposure to organophosphates and carbamates, but it can also be inhibited in the presence of other pollutants as some organochlorine insecticides and heavy metals. The only chemical of the organochlorine group that has its use legally permitted is the endosulfan. It is widely used in several crops including soybean, wheat, corn, cotton, fruits and vegetables and is less persistent in the environment in comparison with other clorinated compounds. Even so, it is classified by the U.S.EPA as highly toxic. The aim of this research is to study the effects of endosulfan on cholinesterase activity of the tropical fish Ancystrus sp.. Fish were exposed intracelomatically with $4 \mathrm{mg} / \mathrm{kg}$ of technical grade endosulfan (97\%). After 24,48 and 96 hours of exposure fishes were killed for muscle collection. These samples were used for cholinesterase activity measurement. The enzymatic inhibition was observed in exposed fishes in comparison to the control group $(p<0,05)$. The obtained results show that endosulfan at a $4 \mathrm{mg} / \mathrm{kg}$ concentration is able to cause cholinesterase inhibition. Further experiments have been done with other doses to corroborate these results.

Key Words: biomarkers, cholinesterase activity, fish, endosulfan. Financial support: CAPES. 